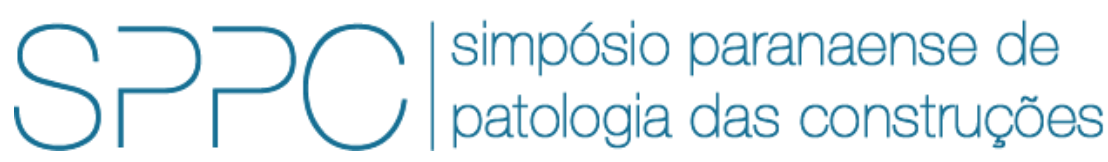

ISSN 2526-7248 artigo 2SPPC2001, pp. 461-473, 2017

\title{
Método exemplificado de inspeções de campo para avaliação de anomalias e manifestações patológicas em barragens de terra
}

\author{
Teixeira, S.H.C ${ }^{1}$; de Souza Júnior, T.F2; Pasqual R.S3; Luz, C.C 4 \\ 1 Doutor e Professor, Universidade Federal do Paraná, sidnteix@outlook.com \\ 2 Mestrando, Universidade Federal do Paraná, tennisonfreire@hotmail.com \\ ${ }^{3}$ Mestrando, Universidade Federal do Paraná, rodrigo@protecengenharia.com.br \\ ${ }^{4}$ Doutorando, Universidade Federal do Paraná, crisccluz@hotmail.com
}

Resumo: Acidentes decorrentes de rupturas de barragens causaram efeitos catastróficos à sociedade em todo o mundo (impactos socioeconômicos e ambientais), induzindo a regulamentação por parte dos governos e consequente responsabilização dos proprietários quanto a manutenção das estruturas. Em 2010 foi criada a Lei no 12.334/2010 [1] que tem como objetivo garantir a observância de padrões de segurança de barragens reduzindo a possibilidade de acidentes e suas consequências. Neste trabalho busca-se apresentar um método exemplificado para realização de inspeções de campo em barragens de terra, para estabelecer um diagnóstico das causas das manifestações patológicas e anomalias encontradas e para analisar a barragem sob os aspectos hidrológicos, de estabilidade e riscos associados. As análises basearam-se nos critérios do Manual de Segurança e Inspeções de Barragens (2002) [2]. As condições de segurança (Risco e Dano Potencial Associado) da barragem fundamentaram-se nos critérios da Lei n 12.334/2010 [1].

Palavras-chave: barragem, ruptura, segurança, inspeções, patologia.

Abstract: Accidents caused by dam breaks resulted in catastrophic consequences to the society all around the world (social, economic and environmental impacts), what led to governments regulation and to the accountability of the dams owners in respect to the structures maintenance. In 2010 the law number 12.334/2010 [1] was created in Brazil with the objective of ensuring the compliance with dam security standards reducing the probability of accidents and its consequences. In this paper it is presented a method with examples concerning the investigation and diagnosis of pathological evidences and hydrological, stability and risks analysis of a homogeneous earth dam. The analysis were based on the Dams Safety and Inspection Manual (2002) [2]. The dam safety conditions evaluations were based on the 12.334/2010 [1] criteria.

Keywords: Dam, Break, Safety, Inspections, Pathology 
TEIXEIRA, S. H. C.; ET AL. MÉTODO EXEMPLIFICADO DE INSPEÇÕES DE CAMPO PARA AVALIAÇÃO DE ANOMALIAS E MANIFESTAÇÕES PATOLÓGICAS EM BARRAGENS DE TERRA. $2^{\circ}$ Simpósio Paranaense de Patologia das Construções (20 SPPC), artigo 2SPPC2001, pp. 461-473, 2017. DOI: 10.4322/2SPPC.2017.038

\section{Introdução}

Devido às graves consequências de um eventual acidente em uma barragem, a necessidade de regulamentação e controles adequados quanto a sua operação e manutenção são mandatórios. A criação da Lei no 12.334/2010 [1] determinou padrões mínimos de segurança e inspeções que devem ser seguidos visando à mitigação de riscos, identificação prévia de manifestações patológicas e problemas que podem culminar em acidentes. Os órgãos de fiscalização do governo federal, ou seja, a Agência Nacional de Águas (ANA) e o Departamento Nacional de Produção Mineral (DNPM), exigem dos proprietários de barragens de terra e rejeitos que sejam realizadas reavaliações de segurança das estruturas e também possibilitaram a criação de projetos de lei para enrijecimento da legislação ambiental.

Avaliações métodicas de anomalias e manifestações patológicas a partir de investigações técnicas e análises ou retroanálises, contribuem para a manutenção da estrutura dentro de critérios desejáveis de segurança. Neste trabalho, apresentase uma metodologia exemplificada de avaliação de estruturas de barragens de terra com requisitos e medidas prescritos no Manual de Segurança e Inspeções de Barragens [2]. Além disso, são mostrados exemplos de aplicações de técnicas de análise geotécnica em uma barragem durante a sua fase operacional.

\section{Materiais e métodos}

Nas etapas descritas a seguir são apresentadas a proposta metodológica estabelecida para identificação, a análise e a avaliação das principais anomalias e manifestações patológicas existentes em barragens de terra homogêneas subsidiando-se dos critérios expostos no Manual de segurança e Inspeções de barragens.

\subsection{Caracterização das manifestações patológicas e anomalias em barragens de terra}

As inspeções de campo devem ocorrer de forma a levantar as possíveis manifestações patológicas e anomalias presentes em cada trecho da barragem. Essas investigações podem detectar possíveis falhas que estão ou podem vir a instabilizar a estrutura da barragem.

A Agência Nacional de Águas possui uma resolução que estabelece normas para as inspeções de segurança regulares das barragens com o intuito de monitorar possíveis anomalias. Devem ser observados aspectos estruturais e também as atividades operacionais de controle, como o funcionamento das comportas e das válvulas. A regularidade dessas inspeções irá depender da classificação da barragem, pela equipe de segurança, quanto ao nível de perigo oferecido. A ANA estabeleceu uma classificação do perigo em: Normal; Atenção; Alerta e Emergência, de acordo com Bergamo [3].

A Figura 1 ilustra a proposta metodológica para investigar as anomalias e manifestações levantadas em campo baseada nas possibilidades da Tabela 1. 
TEIXEIRA, S. H. C.; ET AL. MÉTODO EXEMPLIFICADO DE INSPEÇÕES DE CAMPO PARA AVALIAÇÃO DE ANOMALIAS E MANIFESTAÇÕES PATOLÓGICAS EM BARRAGENS DE TERRA. $2^{\circ}$ Simpósio Paranaense de Patologia das Construções (2० SPPC), artigo 2SPPC2001, pp. 461-473, 2017. DOI: 10.4322/2SPPC.2017.038

Tabela 1: Tipos de manifestações e anomalias em relação a cada trecho

\begin{tabular}{|c|c|c|c|c|}
\hline Talude de montante & Talude de jusante & Crista & $\begin{array}{c}\text { Área à jusante da } \\
\text { barragem }\end{array}$ & Vertedouro e drenagem superficial \\
\hline $\begin{array}{l}\text { *Sumidouros } \\
\text { *Rachaduras ou trincas } \\
\text { grandes } \\
\text { *Deslizamento, } \\
\text { afundamentos ou } \\
\text { escorregamentos } \\
\text { *Taludes ingremes e } \\
\text { bancadas de escavação } \\
\text { "Erosão no contato } \\
\text { reservatório -barragem }\end{array}$ & $\begin{array}{l}\text { *Deslizamento / Charco } \\
\text { *Rachaduras ou trincas } \\
\text { transversais } \\
\text { *Desabamento } \\
\text { *Rachaduras ou trincas } \\
\text { longitudinais } \\
\text { *Afundamentos } \\
\text { "Erosão } \\
\text { *Presença de árvores / } \\
\text { arbustos } \\
\text { *Presença de tocas de } \\
\text { animal } \\
\text { *Área molhada em faixa } \\
\text { horizontal } \\
\text { *Vazamentos vindo das } \\
\text { ombreiras } \\
\text { *Tráfego de gado ou } \\
\text { animais domésticos }\end{array}$ & $\begin{array}{l}\text { *Rachaduras ou trincas } \\
\text { longitudinais } \\
\text { *Deslocamento vertical } \\
\text { *Desabamentos } \\
\text { *Rachaduras ou trincas } \\
\text { transversais } \\
{ }^{*} \text { Crista desalinhada } \\
{ }^{*} \text { Depressões na crista } \\
{ }^{*} \text { Vegetação excessiva } \\
\text { *Buracos de animal } \\
\text { *Voçoroca na crista } \\
\text { *Trilhas ao longo da crista }\end{array}$ & 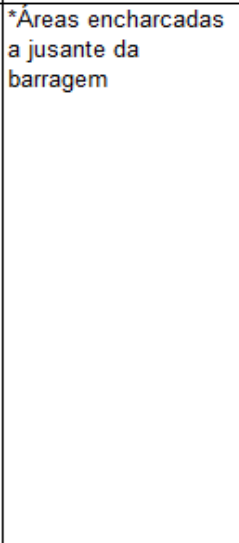 & 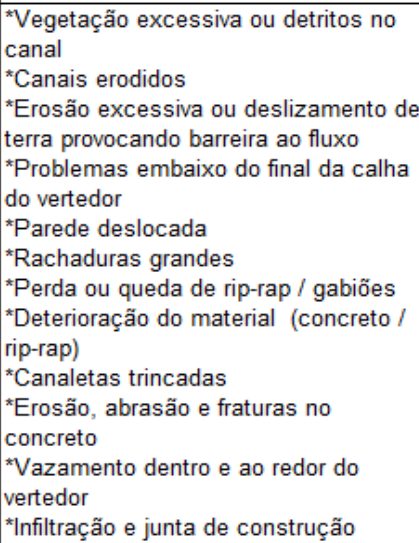 \\
\hline
\end{tabular}

Segundo MI [2], pequenos detalhes devem ser detectados de um determinado ponto, com distâncias médias de 3 a $10 \mathrm{~m}$ em qualquer direção. As trajetórias da inspeção devem ser em ziguezague (subindo e descendo os taludes e também atravessando a crista em diagonal) ou em caminhos paralelos.

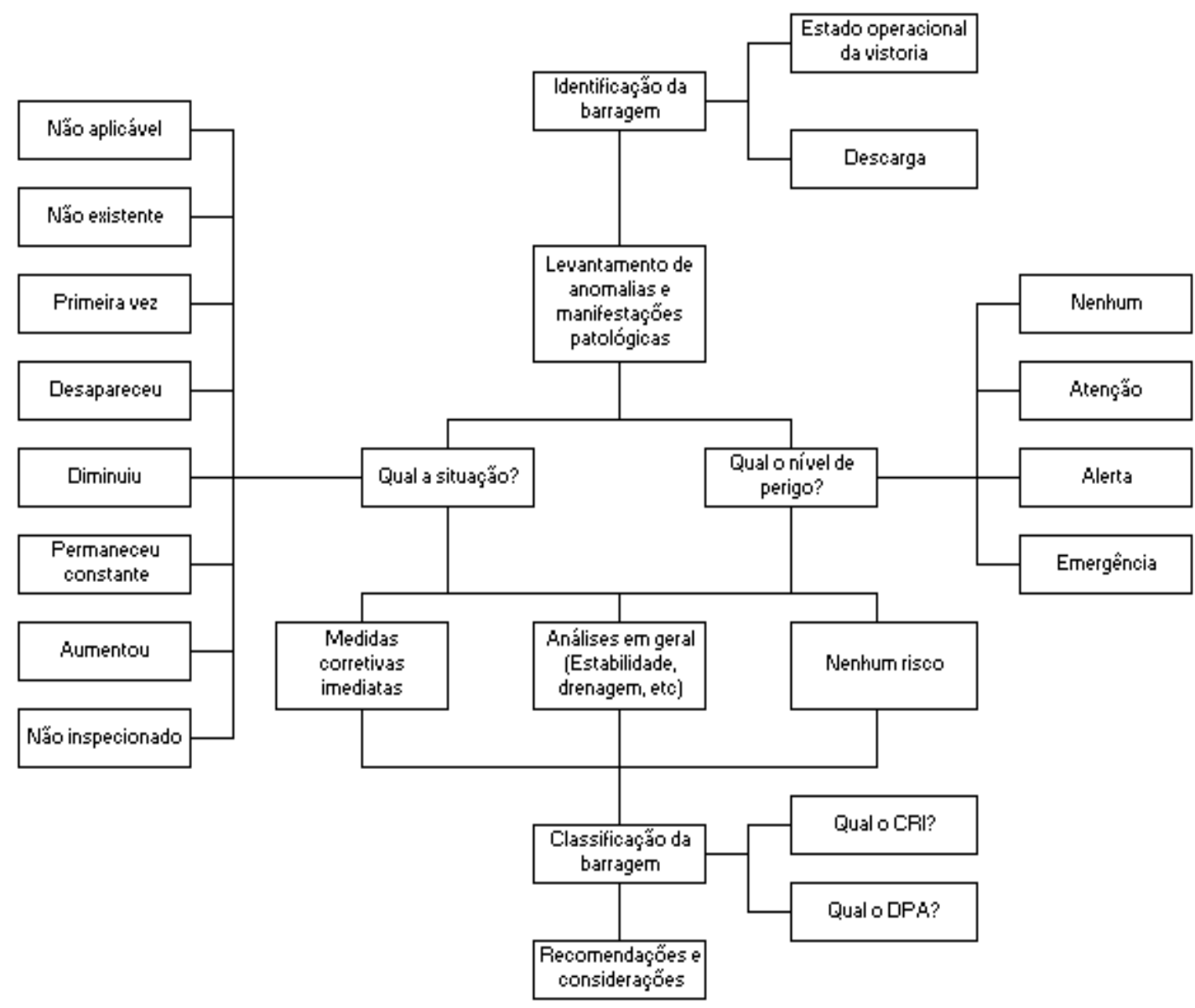

Figura 1: Fluxograma de inspeção técnica de barragens 
Quanto aos níveis de alerta e complexidade, as inspeções subdividem-se em: rotineiras, formais, especializadas e emergenciais. As inspeções regulares devem ser feitas a cada 6 meses, pela equipe do empreendedor. As especiais são realizadas por uma equipe externa multidisciplinar especializada, sendo as frequências temporais das reavaliações informadas no Tabela 2. [2]

Tabela 2: Frequência da reavaliação de segurança de barragens [2]

\begin{tabular}{cc}
\hline Consequência da Ruptura & Período de reavaliações \\
\hline Muito Alta & 5 anos \\
Alta & 7 anos \\
Baixa & 10 anos \\
Muito Baixa & 10 anos \\
\hline
\end{tabular}

\subsection{Realização de inspeção e vistorias "in loco" nos elementos da barragem}

Devem ser realizadas inspeções in loco a fim de descrever a situação atual de cada elemento da barragem de terra, bem como possibilitar avaliações posteriores. Abaixo descrevemos a título de exemplo algumas situações típicas que devem ser observadas durante a inspeção.

\section{Dicussões e Análises}

\subsection{Inspeções de campo e vistorias "in loco"}

Neste item serão demonstras as manifestações patológicas e anomalias mais comumente encontradas em uma estrutura de barragem de terra,com enfase geotécnica.

\subsubsection{Crista da barragem}

Na região crista da barragem, quando revestida com pavimentação asfáltica, deve ser observado se há a existência de trechos danificados em decorrência do crescimento de vegetação, conforme exemplificado pela Figura 2.

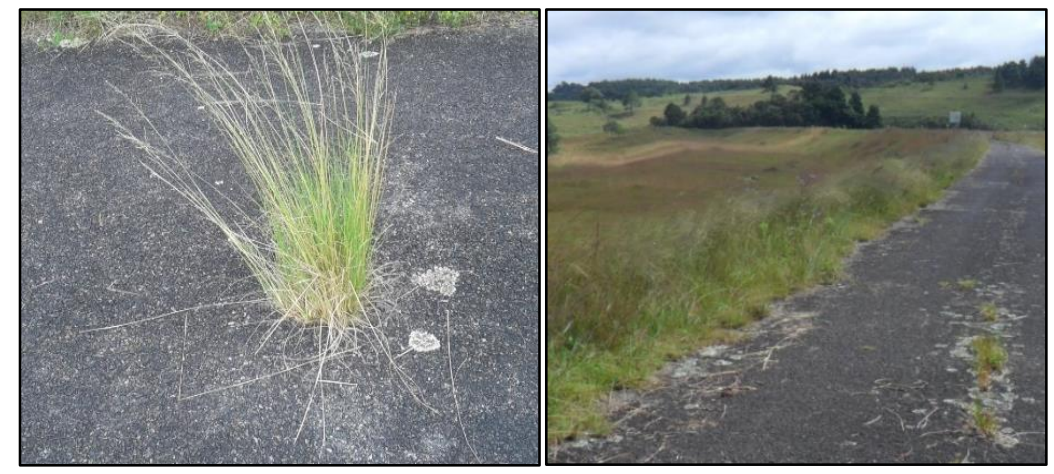

Figura 2: Presença de vegetação na pavimentação da crista da barragem. 
TEIXEIRA, S. H. C.; ET AL. MÉTODO EXEMPLIFICADO DE INSPEÇÕES DE CAMPO PARA AVALIAÇÃO DE ANOMALIAS E MANIFESTAÇÕES PATOLÓGICAS EM BARRAGENS DE TERRA. $2^{\circ}$ Simpósio Paranaense de Patologia das Construções (20 SPPC), artigo 2SPPC2001, pp. 461-473, 2017. DOI: 10.4322/2SPPC.2017.038

Em trechos revestidos deve-se verificar a presença de vegetação densa com presença de resíduos de terra edificados, por exemplo: cupinzeiros (Figura 3), nos taludes de montante e jusante da barragem.

Os cupins e as raízes da vegetação podem criar caminhos preferenciais dentro da barragem de terra, propiciando o escoamento das águas superficiais para dentro do maciço. Diante disto, eles devem ser removidos, conforme o Manual de Segurança e Inspeções de Barragens [2].

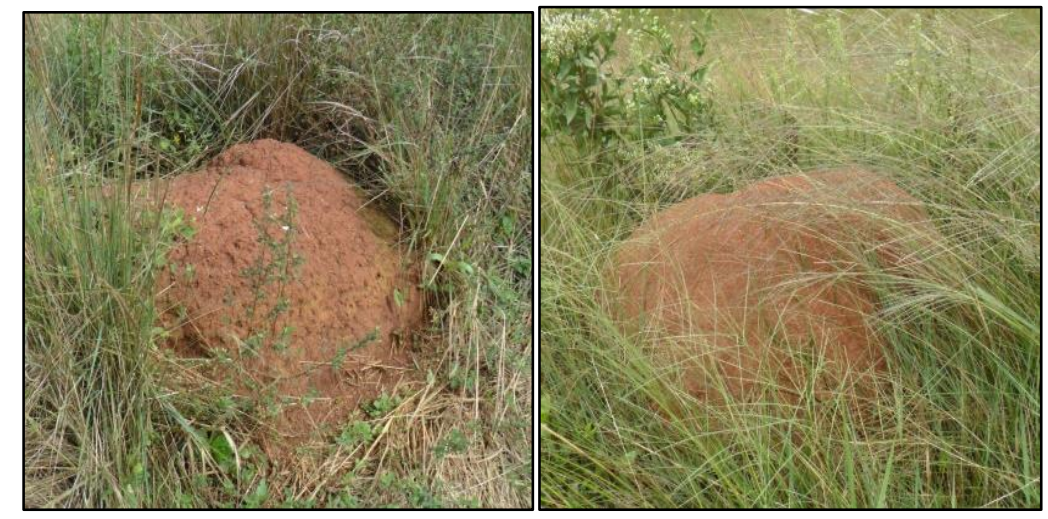

Figura 3: Presença de cupinzeiros e vegetação densa na crista da barragem.

\subsubsection{Talude Montante}

Como pode ser observado na Figura 4, na face montante da barragem deve ser observada a existência de processos de segregação do rip-rap, que impedem a proteção do talude dos choques das ondas do reservatório. A ação de ondas pode provocar o arraste dessas partículas que protegem o barramento e expor a face do talude de terra à ação erosiva mais intensa.

A existência de vegetação com raízes profundas pode criar caminhos preferenciais para a percolação da água, o que pode, por consequência, desencadear o piping na barragem, além de ser um possível abrigo de pequenos animais que podem abrir tocas no maciço. Recomenda-se, nesses casos, a remoção da vegetação e recuperação do rip-rap.
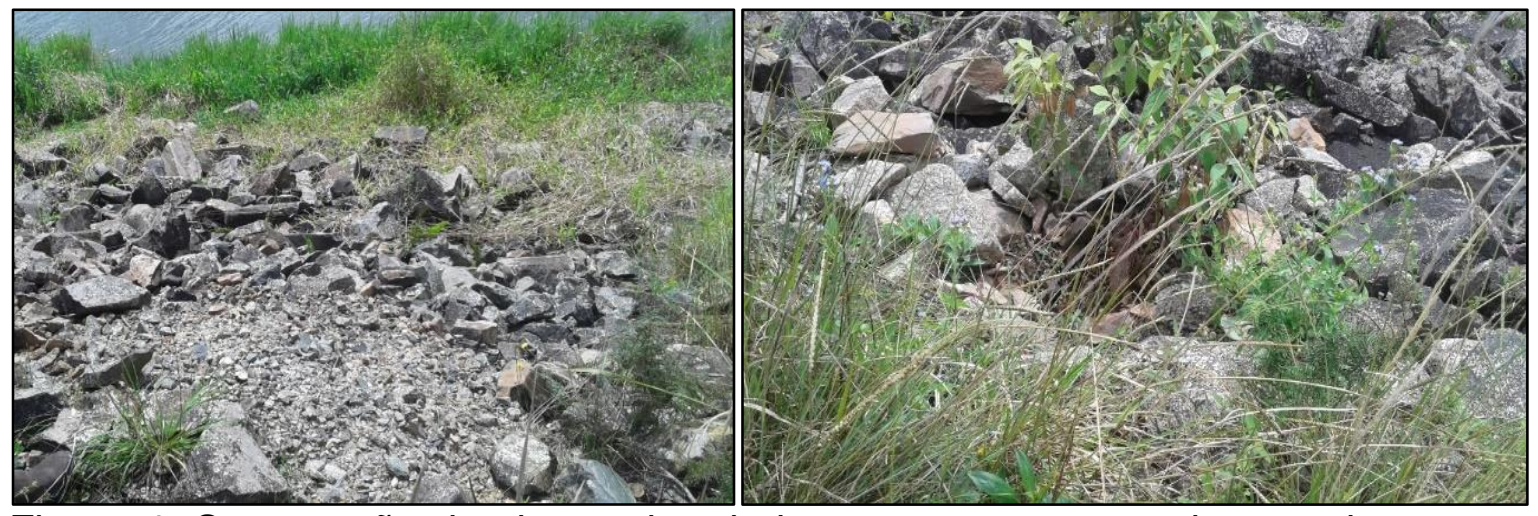

Figura 4: Segregação do rip-rap do talude montante e o crescimento de pequenos arbustos entre os vazios. 
TEIXEIRA, S. H. C.; ET AL. MÉTODO EXEMPLIFICADO DE INSPEÇÕES DE CAMPO PARA AVALIAÇÃO DE ANOMALIAS E MANIFESTAÇÕES PATOLÓGICAS EM BARRAGENS DE TERRA. $2^{\circ}$ Simpósio Paranaense de Patologia das Construções (20 SPPC), artigo 2SPPC2001, pp. 461-473, 2017. DOI: 10.4322/2SPPC.2017.038

\subsubsection{Talude Jusante}

Deve ser observado, no talude a jusante, se ocorrem falhas na vegetação próxima às canaletas de drenagem, conforme retratado na Figura 5. A ocorrência de falhas na vegetação pode ter como consequências o carreamento de solo para o interior das canaletas, obstruindo-as, assim como a evolução de processo erosivo no talude, segundo Manual de Segurança e Inspeções de Barragens [2].

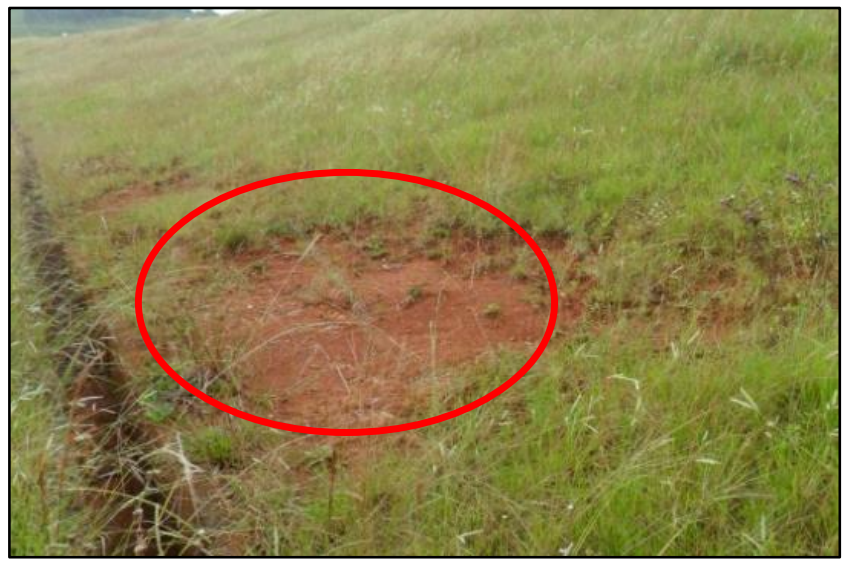

Figura 5: Erosão superficial no talude jusante, próximo às canaletas de drenagem.

Com relação aos taludes da crista, deve-se observar se há sinais de deformações. Essas deformações podem ser decorrentes do assentamento da estrutura após a conclusão das obras (recalques no aterro ou fundação), ou, mais provavelmente, pela fluência do solo em função das variações cíclicas de umidade do maciço (Figura 6).

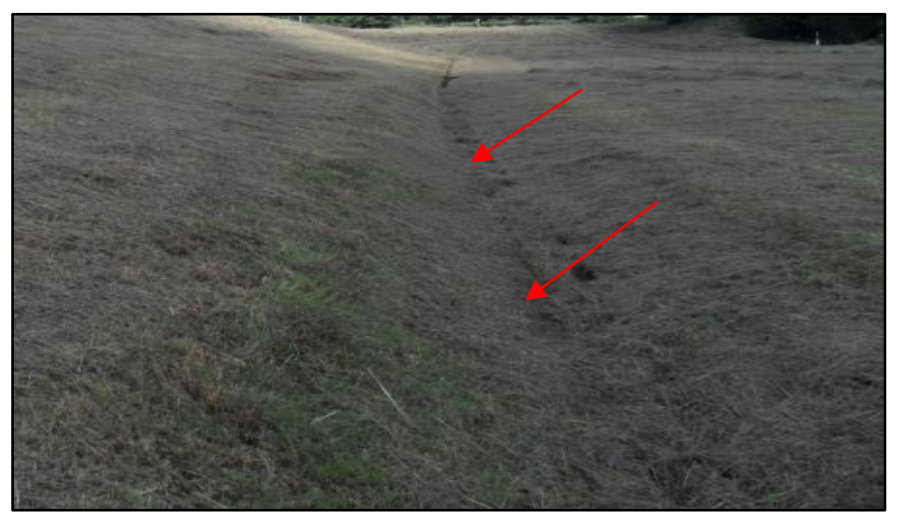

Figura 6: Deformações de talude jusante

Se as deformações identificadas não demandam intervenção imediata, recomendase seu monitoramento através de marcos superficiais.

Verifica-se na Figura 7 que, ao longo de um talude de jusante, na região próxima da canaleta de drenagem de uma berma, foram observadas áreas de umedecimento, indicando a ocorrência de surgências nesses trechos.

As áreas molhadas podem ser decorrentes do aumento excessivo de pressões intersticiais no corpo da barragem e/ou fundação. A fonte de umedecimento do 
TEIXEIRA, S. H. C.; ET AL. MÉTODO EXEMPLIFICADO DE INSPEÇÕES DE CAMPO PARA AVALIAÇÃO DE ANOMALIAS E MANIFESTAÇÕES PATOLÓGICAS EM BARRAGENS DE TERRA. $2^{\circ}$ Simpósio Paranaense de Patologia das Construções (20 SPPC), artigo 2SPPC2001, pp. 461-473, 2017. DOI: 10.4322/2SPPC.2017.038

maciço deve ser investigada e monitorada por meio de piezômetros, tendo em vista que as pressões de água podem ocasionar a perda de resistência do maciço, segundo o Manual de Segurança e Inspeções de Barragens [2] (ver Figura 8). E possivel que barragens nessa situação apresentem problemas relativos a subpressões elevadas dependendo do nível da linha freática e poropressão.

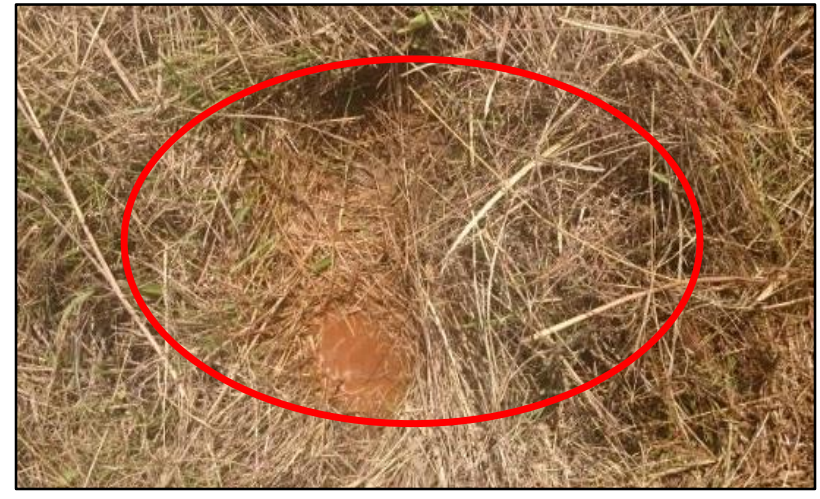

Figura 7: Pontos de umedecimento

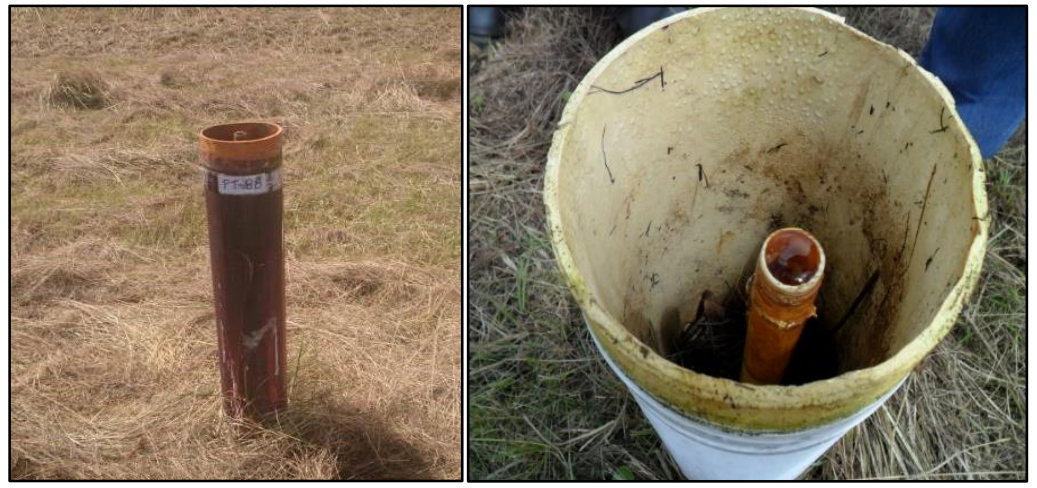

Figura 8: Piezômetro inspecionado com problemas de transbordamento

\subsubsection{Vertedouro}

Com o vertedouro em operação, deve-se observar a uniformidade do perfil de água. Se forem notados pontos localizados com desvio no perfil de água (ver Figura 9), eles podem indicar irregularidades na superfície do concreto, podendo ser associadas com incrustações ou perfurações no concreto. Há de se prever a dificuldade e, até mesmo, a impossibilidade de inspeção da base do canal rápido devido a presença de lâmina d'água. Sendo assim, deve-se inspecionar a integridade da estrutura dos muros laterais do vertedouro e do canal rápido, bem como condições de deságue na bacia amortecedora. 


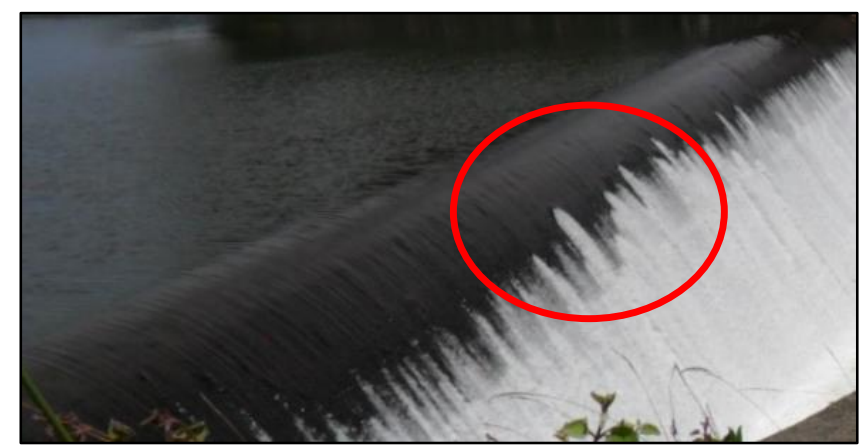

Figura 9: Pontos de desvio no perfil de água do vertedouro

Nos muros laterais do vertedouro e do canal rápido, deve-se verificar a ocorrência de manifestações patológicas do concreto, decorrente, em sua maioria, pela combinação da idade da estrutura, da ação abrasiva do fluxo da água e de reações álcaliagregado. Dentre elas estão: o desgaste superficial do concreto (Figura 10), o desenvolvimento de fissuras (Figura 11Erro! Fonte de referência não encontrada.) e a ocorrência de eflorescências e possíveis processos corrosivos das armaduras em outros pontos. Nessas estruturas de concreto armado são necessários o tratamento da corrosão das armaduras, a injeção das fissuras e a proteção superficial da estrutura.

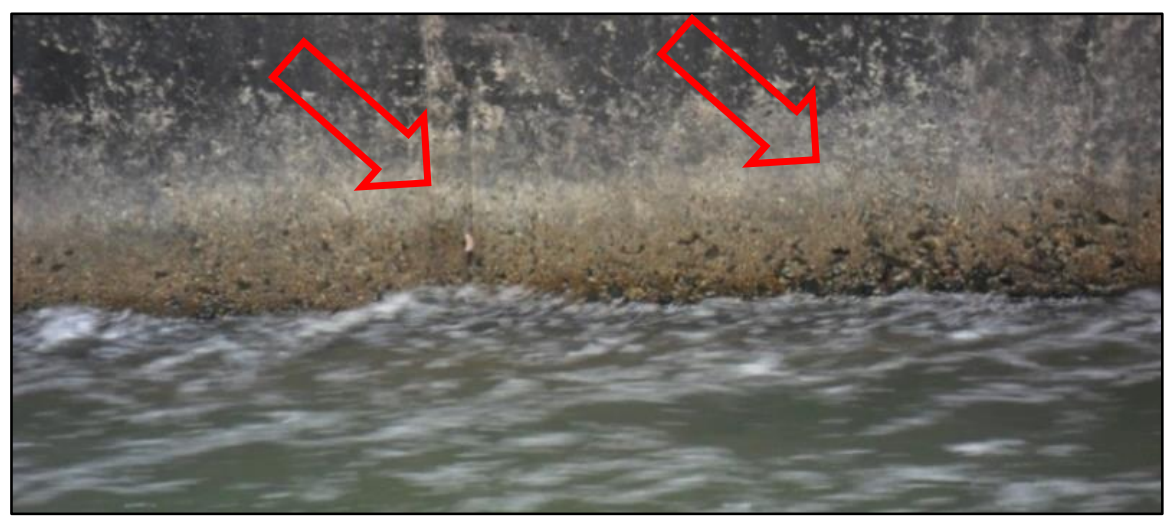

Figura 10: Desgaste superficial do concreto

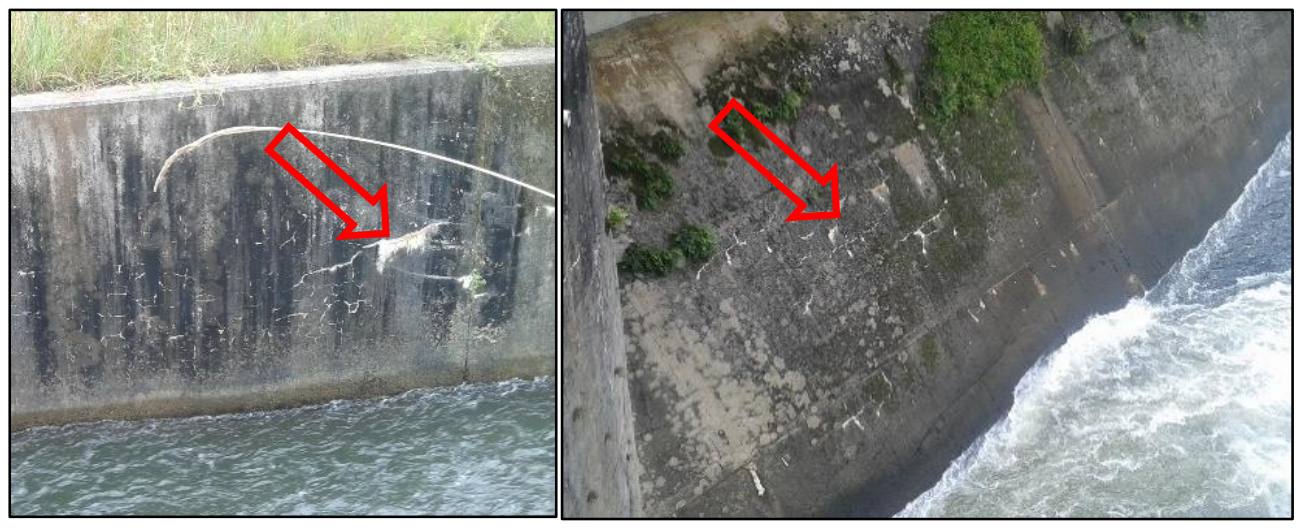

Figura 11: Fissuras e eflorescências no muro frontal do canal extravasor. 
TEIXEIRA, S. H. C.; ET AL. MÉTODO EXEMPLIFICADO DE INSPEÇÕES DE CAMPO PARA AVALIAÇÃO DE ANOMALIAS E MANIFESTAÇÕES PATOLÓGICAS EM BARRAGENS DE TERRA. $2^{\circ}$ Simpósio Paranaense de Patologia das Construções (20 SPPC), artigo 2SPPC2001, pp. 461-473, 2017. DOI: 10.4322/2SPPC.2017.038

\subsubsection{Canaletas e Casa de Leitura}

Nas canaletas verificadas em que há grande acúmulo de água, pode-se considerar a existência de obstruções, acúmulos de resíduos sólidos ou, então, que sua declividade é inadequada para escoamento da água drenada (Figura 12).

É possivel, também, que as casas de leituras apresentem uma grande quantidade de água empoçada em seus interiores, com fluxo constante para o talude, conforme Figura 13, saturando-0.

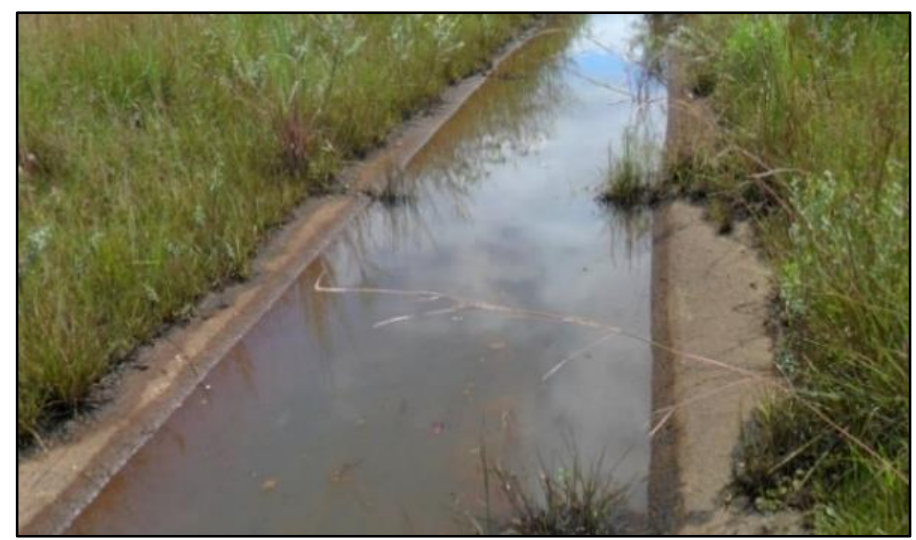

Figura 12: Canaleta próxima a um dreno de pé de talude com empoçamento de água.

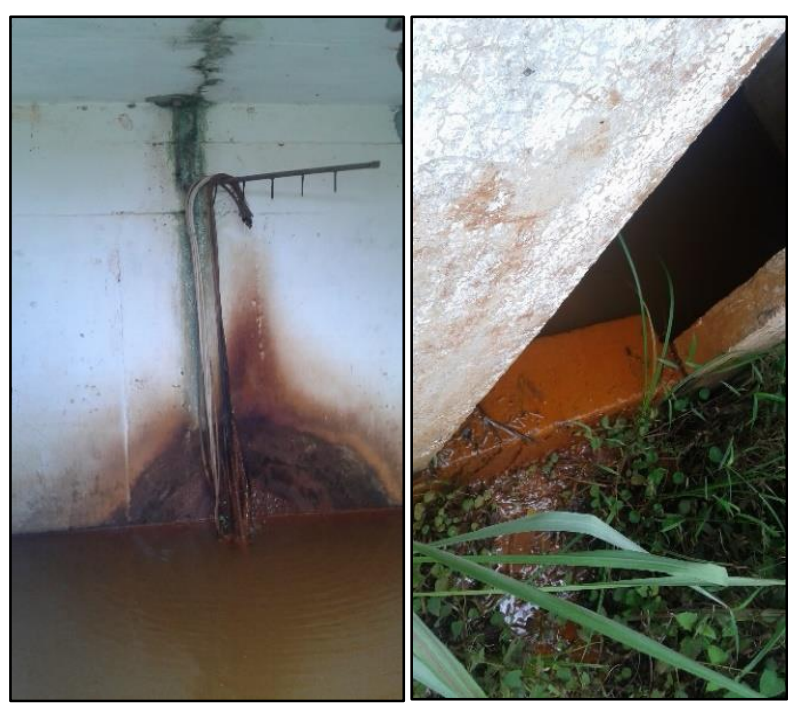

Figura 13: Casa de leitura com presença de carreamento de finos e empoçamentos

Neste sentido, o carreamento de finos através da tubulação de instrumentos de monitoramento, pode levar à formação de caminhos preferenciais de percolação no interior do maciço, podendo, inclusive, desencadear a ocorrência de piping. Além das anomalias e manifestações patológicas citadas, deve-se verificar questões pontuais de empoçamentos, as condições das instalações elétricas, desgastes das estruturas de concreto armado da torre de captação, bem como encharcamento do solo oriundo da desgaste da tubulação de saída de fundo. 
TEIXEIRA, S. H. C.; ET AL. MÉTODO EXEMPLIFICADO DE INSPEÇÕES DE CAMPO PARA AVALIAÇÃO DE ANOMALIAS E MANIFESTAÇÕES PATOLÓGICAS EM BARRAGENS DE TERRA. $2^{\circ}$ Simpósio Paranaense de Patologia das Construções (20 SPPC), artigo 2SPPC2001, pp. 461-473, 2017. DOI: 10.4322/2SPPC.2017.038

\subsection{Análises utilizadas na avaliação de segurança de barragens}

Nos itens subsequentes são apresentadas técnicas utilizadas em barragens de terra e enrocamento, bem como de rejeitos minerais, de modo a atender os critérios de segurança das normas, assim como exemplos de aplicação.

\subsubsection{Análises hidrológicas}

A vazão crítica do estudo é obtida a partir de chuvas com uma determinada duração. Por exemplo, na Figura 14 foi ilustrado um hidrograma de entrada com período de retorno de 10.000 anos e chuvas de $16 \mathrm{~h}$ de duração. Para verificação do sistema extravasor de cheias e da cota de coroamento da barragem, interessam as chuvas com maior duração, que podem representar uma situação equivalente dos chamados repiques de várias chuvas rápidas.

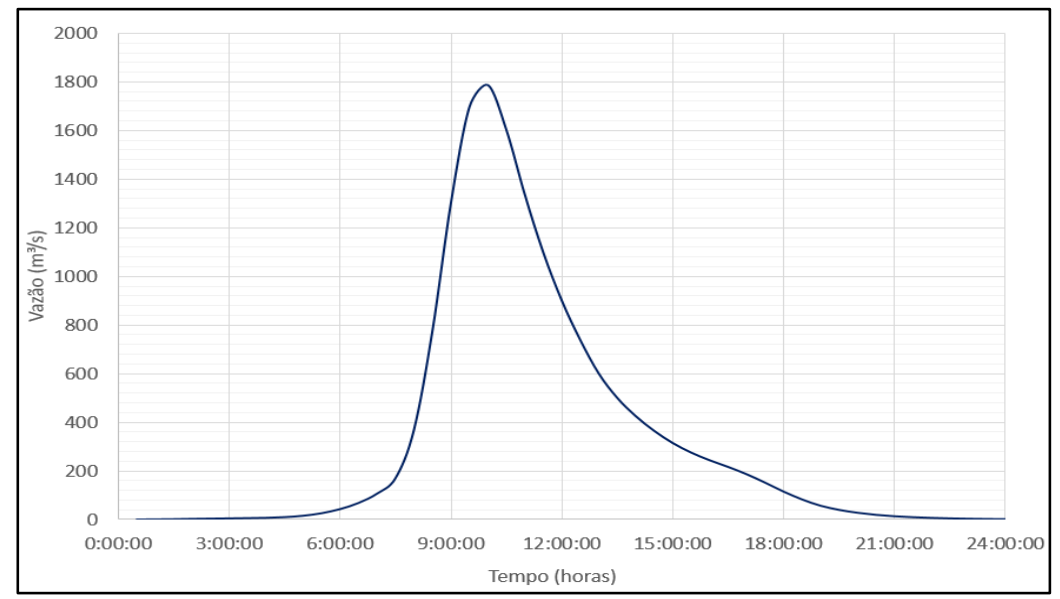

Figura 14: Exemplo de Hidrograma afluente.

Considerando a geometria do vertedouro existente é estimado o volume de extravasão do dispositivo. Desta forma, é plotada uma curva chave do vertedouro (ver Figura 15). A partir dessa curva são obtidas as vazões efluentes conforme a variação do nível d`água do reservatório. Conhecendo-se a cota do nível do reservatório, é possível avaliar o bordo livre da barragem usando recomendações da USBR (U.S Bureau of Reclamation) [4].

O hidrograma efluente depende, fundamentalmente, do nível de água na bacia de detenção e do tipo de estrutura hidráulica utilizada para o controle da vazão. O canal rápido tem de ter capacidade de ser compatível com a vazão extravasada pelo vertedor da barragem. A partir das características geométricas, a capacidade do canal é reavaliada.

Por fim, para melhor compreender os princípios do amortecimento de ondas de cheias no reservatório, deve-se analisar o conceito de volume de amortecimento. Uma das consequências da implantação de um barramento é a formação de volumes de acumulação, onde cada cota ou nível atingido pelo lago corresponde um valor de volume de água armazenado, contido pelas várzeas, encostas e pelo maciço da barragem. 


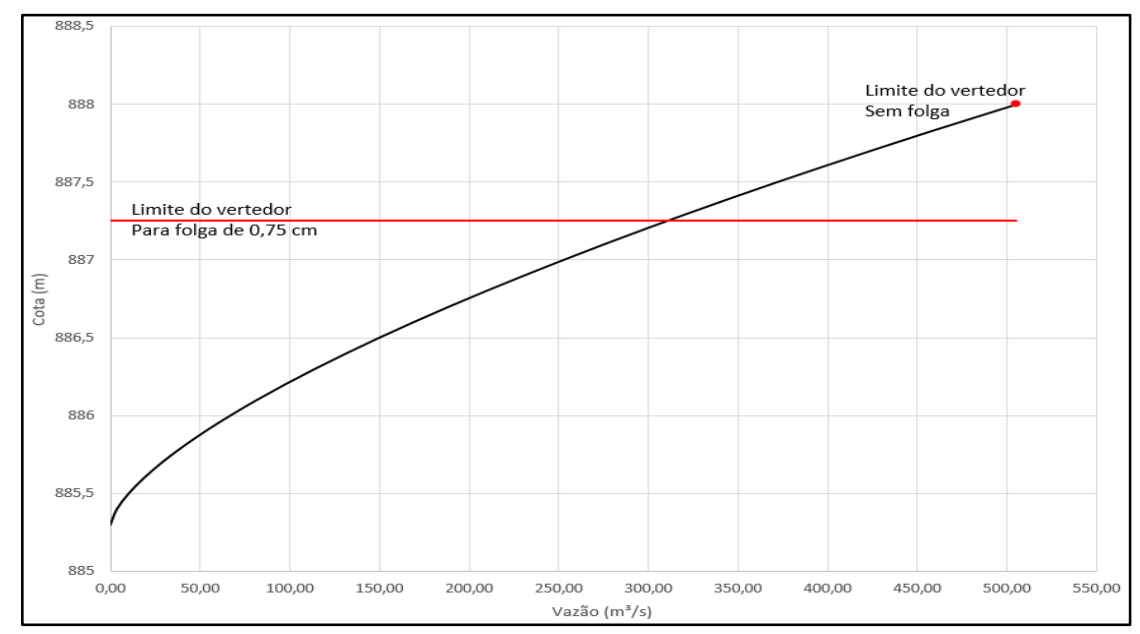

Figura 15: Curva chave do vertedouro

\subsubsection{Análises de estabilidade}

Um escorregamento de massa decorre de um desequilíbrio de esforços, ou seja, as tensões solicitantes excedem a resistência ao cisalhamento do solo do aterro, sendo possível a realização das análises de estabilidade destes taludes a partir de duas abordagens: Determinística e Probabilística. É comum o uso da teoria do equilíbrio limite fundamentada numa abordagem determinística em que a avaliação da segurança do talude é feita através do balanço entre esforços resistentes e solicitantes da cunha obtendo um fator de segurança (FS) global.

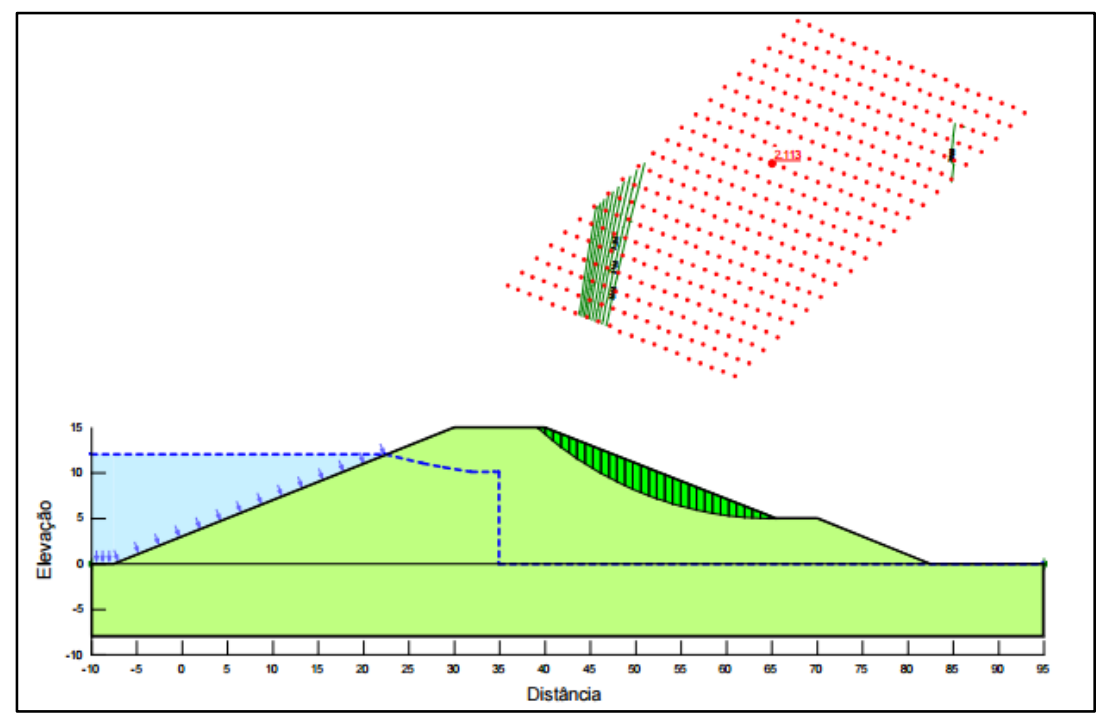

Figura 16: Avaliação de estabilidade de taludes em fase operacional

Segundo o MI [2], o critério de fator de segurança adotado para barragens em condições de carregamento permanente do nível normal máximo do reservatório é $\mathrm{FS} \geq 1,5 \mathrm{em}$ trecho de talude jusante (ver Figura 16). Além disso, devem ser consideradas superfícies potenciais de ruptura cilíndricas, com profundidade mínima de $1,5 \mathrm{~m}$. As análises de estabilidade podem ser processadas através do programa Slope/W, (Geo-Slope®) com o uso do método de Spencer e/ou Morgenstern-Price, que são método rigorosos. 
TEIXEIRA, S. H. C.; ET AL. MÉTODO EXEMPLIFICADO DE INSPEÇÕES DE CAMPO PARA AVALIAÇÃO DE ANOMALIAS E MANIFESTAÇÕES PATOLÓGICAS EM BARRAGENS DE TERRA. $2^{\circ}$ Simpósio Paranaense de Patologia das Construções (20 SPPC), artigo 2SPPC2001, pp. 461-473, 2017. DOI: 10.4322/2SPPC.2017.038

\subsubsection{Análise de classificação de riscos de barragens}

A Portaria Águas Paraná ํo 14 [5] possibilita a classificação da barragem através dos critérios da Resolução 143/2012 [6]. Essa resolução categoriza barragens de qualquer método construtivo e magnitude nos limites do território brasileiro. Os níveis de riscos podem ser três: alto, médio ou baixo, em função das características técnicas, estado de conservação do empreendimento e do atendimento ao plano de segurança da barragem. Concomitantemente a isso, na análise deve ser avaliado o Dano Potencial Associado (DPA) [5] que considera os seguintes critérios: volume do reservatório, potencial de perdas humanas, impacto ambiental e socioeconômico.

\section{Considerações finais}

O presente trabalho apresentou uma sequência metodológica exemplificada com as anomalias e manifestações patológicas comumente observadas em barragens de terra homogênea.

A padronização de uma metodologia de inspeção técnica ajuda a minimizar custos e tempo envolvidos na investigação, na concepção de um diagnóstico e na elaboração e emissão de relatórios técnicos.

Frequentemente, as barragens vistoriadas apresentam manifestações patológicas. Nestes casos, a título de exemplificação, devem ser adotadas medidas como: recomposição de rochas do rip-rap; roçagem de vegetação; limpeza das canaletas de drenagem; recomposição da vegetação do corpo do talude; remoção de vegetação e arbustos dos elementos drenantes e trecho montante; remoção de cupinzeiros; entre outras, constituindo medidas corretivas pouco complexas de manutenção da estabilidade e vida útil da barragem.

Fazer um levantamento considerando o nível de perigo e situação das partes e componentes da estrutura pode ajudar na classificação em ordem de importância e urgência de intervenções corretivas na estrutura de barragem. À medida em que as anomalias e as manifestações patológicas forem mais impactantes devem-se priorizar obras de reestabelecimento da estrutura.

O processo unificado das análises hidrológicas, de estabilidade e de risco baseado nos procedimentos da Figura 1 geram informações que uma vez combinadas às inspeções de campo permitem um entendimento significativo do comportamento das barragens, além de diligenciar às medidas corretivas.

Trabalhos com esta visão auxiliam na consolidação e formalização de meios para atendimento do instrumento da Política Nacional de Segurança de Barragens (PNSB), quanto ao plano de segurança de barragens.

\section{Agradecimentos}

Os autores agradecem ao Conselho Nacional de Desenvolvimento Científico e Tecnológica (CNPq) pelo apoio financeiro gerado através das bolsas de pesquisa 
TEIXEIRA, S. H. C.; ET AL. MÉTODO EXEMPLIFICADO DE INSPEÇÕES DE CAMPO PARA AVALIAÇÃO DE ANOMALIAS E MANIFESTAÇÕES PATOLÓGICAS EM BARRAGENS DE TERRA. $2^{\circ}$ Simpósio Paranaense de Patologia das Construções (20 SPPC), artigo 2SPPC2001, pp. 461-473, 2017. DOI: 10.4322/2SPPC.2017.038

e ao Programa de Pós-Graduação de Engenharia de Construção Civil da Universidade Federal do Paraná (PPGECC).

\section{Referências}

[1] BRASIL. Lei no 12.334, de 20 de Setembro de 2010.

[2] MI. Ministério da Integração Nacional. Manual de segurança e inspeção de barragens. Brasília, p. 138. 2002.

[3] BERGAMO, R.L. Normas para inspeção de barragens.Net, São Paulo, Dez. 2011. Energia. Disponível em: $<$ http://infraestruturaurbana.pini.com.br/solucoes-tecnicas/10/normas-parainspecao-de-barragens-agencia-nacional-das-aguas-243473-1.aspx>. Acesso em 20 Fev. 2017.

[4] BUREAU OF RECLAMATION. Design Standards No. 13: Embankment Dams. 2012.

[5] ÁGUASPARANÁ. Portaria n 14, 26 de março de 2014.

[6] BRASIL. Resolução $n^{\circ}$ 143, de 10 de Julho de 2012. Estabelece critérios gerais de classificação de barragens por categoria de risco, dano potencial associado e pelo volume do reservatório, em atendimento ao art. $7^{\circ}$ da Lei $n^{\circ}$ 12.334, de 20 de setembro de 2010. Diário Oficial da União, Brasil, 04 de Setembro de 2012. Disponível em: http://www.cnrh.gov.br/index.php?option=com_docman\& task=doc_download\&gid=1635>. Acesso em: $\overline{21}$ Jan. 2017. 